\title{
Preoperative Mental Health Status of Living Kidney Donors
}

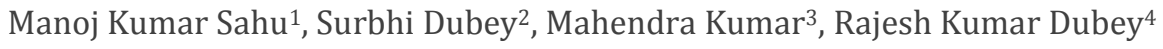 \\ 1, 2, 3,4 Department of Psychiatry, Dr. Bhimrao Ambedkar Memorial Hospital, Raipur, Chhattisgarh, India.
}

\section{ABSTRACT}

\section{BACKGROUND}

Pre-operative psychiatric assessment is mandatory for all organ donors in India as per the "Transplantation of Human Organs Act". All prospective organ donors are assessed to find out the psychological and intellectual fitness to donate organs. We wanted to find out the preoperative mental health status of living kidney donors.

\section{METHODS}

This is a descriptive study, done from case records. Case record files of all prospective kidney donors between January 2017 and December 2018 were reviewed. Subjects were assessed on SCID (Structured Clinical Interview for DSM IV) and HADS (Hospital Anxiety and Depression Scale) for mental health status.

\section{RESULTS}

Out of 139 subjects, 35 were males (25.2\%) and 145 were females (74.8\%). The mean age of donors was 45.58 years. Majority of donors (54.0\%) were blood relatives of the recipient. None of the subjects had any Axis-I psychiatric disorder. First degree related donors reported low level of anxiety than non-related donors.

\section{CONCLUSIONS}

None of the donors had any current or lifetime Axis I diagnosis. Relationship with the recipient was found to be the most significant motivating factor for organ donation and the probable protective factor against psychological distress.

\section{KEY WORDS}

Kidney Donors, Mental Health Status, Anxiety, Depression
Corresponding Author: Dr. Surbhi Dubey, Assistant Professor, Department of Psychiatry,

Dr. Bhimrao Ambedkar Memorial Hospital, Raipur, Chhattisgarh, India.

E-mail:drsm16@yahoo.co.in

DOI: $10.14260 / j e m d s / 2020 / 778$

How to Cite This Article:

Sahu MK, Dubey S, Kumar $M$, et al. Preoperative mental health status of living kidney donors. J Evolution Med Dent Sci 2020;9(47):3547-3550, DOI: $10.14260 /$ jemds/2020/778

Submission 28-04-2020, Peer Review 10-10-2020, Acceptance 16-10-2020, Published 23-11-2020.

Copyright (C) 2020 Manoj Kumar Sahu et al. This is an open access article distributed under Creative Commons Attribution License [Attribution 4.0 International (CC BY 4.0)] 


\section{BACKGROUND}

Globally, Chronic Kidney Disease (CKD) is associated with high morbidity and mortality with approximately 735,000 deaths annually. Thus, CKD is the $12^{\text {th }}$ most common cause of death and the $17^{\text {th }}$ most common cause of disability. ${ }^{1}$ In the final stage of CKD (i.e., stage 5 or End Stage Renal Disease [ESRD]), renal replacement therapy (RRT) such as dialysis or kidney transplantation becomes necessary to maintain life. The number of organ donation is increasing worldwide. As per the National Organ and Tissue Transplant Organization (NOTTO) data, there is a constant rise in the rate of kidney transplantation in India (from 3.22 per million populations in 2013 to 5.86 per million populations in 2018). ${ }^{2}$

The number of living kidney donations is increasing worldwide ${ }^{3}$ comprising approximately $30 \%-50 \%$ of all kidney transplants in high-income countries, with the majority of donors being parents, spouses or siblings. ${ }^{4-7}$ Organ transplantation is special condition for the medical and ethical point of view. Pre-operative psychiatric assessment is mandatory for all organ donors in India as per the "Transplantation of Human Organs Act", the primary legislation related to organ donation and transplantation in India regulates the removal, storage and transplantation of human organs for therapeutic purpose. As a part of the regulation, all prospective organ donors are assessed to find out the psychological and intellectual fitness to donate organs. There is important need to find out the preoperative mental health status of living kidney donors. From an evolutionary perspective, donor's lack of concern about their own wellbeing can be seen as an altruistic behaviour to increase patient's fitness at the (potential) expense of their own fitness.

\section{METHODS}

The present study was conducted at Dr. B. R. Ambedkar Memorial Hospital, Raipur which is the nodal office of the Chhattisgarh State Human Organ Transplant Committee. Preoperative psychiatric assessment of prospective donors is mandatory as per the Transplantation of Human Organs Act 1994. All prospective donors are assessed on SCID (Structured Clinical Interview for DSM) and HADS-Hindi (Hospital Anxiety and Depression Scale-Hindi) as a part of the departmental SOP for human organ transplant. Present study was a descriptive study done from case records files. Case record files of all prospective kidney donors between January 2017 and December 2018 were reviewed. A specially designed proforma was used to retrieve socio demographic data and SCID, HADS scores from the case record files.

\section{Instruments}

\section{SCID}

The SCID is a semi structured clinical interview designed to assess the presence of selected DSM-IV axis I diagnoses. ${ }^{8}$ The instrument is administered by a trained clinical interviewer or mental health professional (author MS is a certified SCID rater) and uses a modular format with skip patterns within diagnostic sections. When criteria for a given diagnosis are met, the diagnosis is scored in terms of its life time prevalence and its presence in the past month.

\section{HADS}

The Hospital Anxiety and Depression Scale ${ }^{9}$ is a 14 -item measure designed to assess anxiety and depression symptoms in medical patients, (seven items related to anxiety and seven related to depression) with emphasis on reducing the impact of physical illness on the total score. Items are rated on a 4point severity scale. The HADS produces two scales, one for anxiety (HADS - A) and one for depression (HADS - D), differentiating the two states. Scores of greater than or equal to 11 on either scale indicate a definitive case.

\section{Statistical Analysis}

Data was entered manually into a datasheet and analyzed. All 139 participants were included for data calculation. Data was analyzed with Statistical Package for the Social Sciences (SPSS) Version 16.0. An analysis of descriptive statistics was conducted to illustrate the demographic and other selected characteristics of the sample. Independent sample t-test was used to explore the significant differences in anxiety scores between sample characteristics non-related donor (including spouse) and blood related donors.

\section{RESULTS}

\section{Demographic Characteristics}

Majority of the donors were females $(74.8 \%, \mathrm{n}=145)$. The mean age of donors was 45.58 years (SD - 10.39). The highest percentage of donors were in the age group of 36 - 50 years $(46.0 \% \mathrm{n}=64)$. Majority of the donors (54\%) were blood relatives of the recipient. Detail demographic profile is shown in Table 1.

\begin{tabular}{|c|c|c|}
\hline \multicolumn{3}{|c|}{ Variable 139 (\%) } \\
\hline \multicolumn{3}{|c|}{ Age Groups (Years) } \\
\hline $20-35$ & 26 & 18.7 \\
\hline $36-50$ & 64 & 46.0 \\
\hline $51-70$ & 49 & 35.3 \\
\hline \multicolumn{3}{|c|}{ Gender } \\
\hline Male & 35 & 25.2 \\
\hline Female & 104 & 74.8 \\
\hline \multicolumn{3}{|c|}{ Marital Status } \\
\hline Unmarried & 1 & .7 \\
\hline Married & 132 & 95.0 \\
\hline Widow & 6 & 4.3 \\
\hline \multicolumn{3}{|c|}{ Locality } \\
\hline Rural & 93 & 66.9 \\
\hline Urban & 46 & 33.1 \\
\hline \multicolumn{3}{|c|}{$\begin{array}{c}\text { Concerns of the Living Kidney Donor Candidates Based on Their Relationship } \\
\text { with the Recipient }\end{array}$} \\
\hline Spouse & 43 & 30.9 \\
\hline Blood Relatives & 75 & 54.0 \\
\hline $\begin{array}{l}\text { Non Blood Relatives } \\
\text { (Others) }\end{array}$ & 21 & 15.1 \\
\hline \multicolumn{3}{|c|}{ Anxiety } \\
\hline Normal & 78 & 56.1 \\
\hline Borderline Abnormal & 61 & 43.9 \\
\hline Severe & 00 & 00 \\
\hline \multicolumn{3}{|c|}{ Depression } \\
\hline Normal & 139 & 100.0 \\
\hline Borderline Abnormal & 00 & 00 \\
\hline Severe & 00 & 00 \\
\hline
\end{tabular}


None of the donors had any Axis-I psychiatric disorder as assessed on SCID. Mean depression score on HADS was 5.19 (Figure 1). (Blood relative donor - $5.29 \&$ non-related (spouse) donor - 4.88., p-non significant).

Mean anxiety score on HADS was 6.93; (blood relatives donor $-5.72 \&$ non related (spouse) donor - 8.39). There was significant difference in anxiety scores between nonrelated (spouse) donor and blood related donors $(\mathrm{p}=.000, \mathrm{t}=8.455$, $\mathrm{df}=116$; mean difference -2.675 ; confidence interval: 2.05 . 3.30) (Figure 1). Male donors of spouse and non-blood relatives group had high anxiety in comparison to blood relative's male to female donors (Table 2).

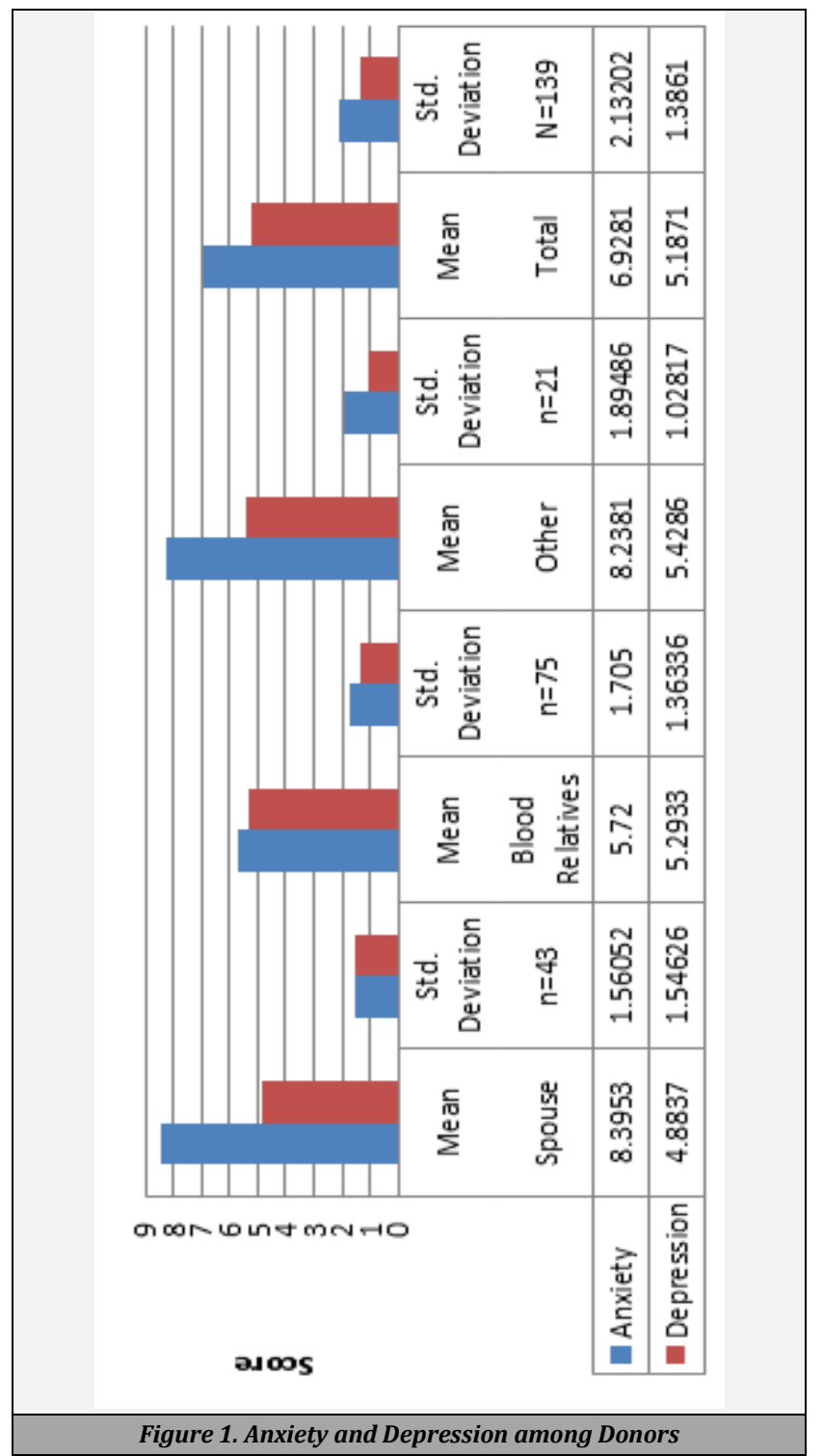

\begin{tabular}{|ccccc|}
\hline Donor Group & Gender & Mean & N & Std. Deviation \\
& Male & 9.6667 & 3 & .57735 \\
Spouse & Female & 8.3000 & 40 & 1.57219 \\
& Total & $\mathbf{8 . 3 9 5 3}$ & $\mathbf{4 3}$ & $\mathbf{1 . 5 6 0 5 2}$ \\
& Male & 5.7143 & 21 & 1.41926 \\
Blood Relatives & Female & 5.7222 & 54 & 1.81624 \\
& Total & $\mathbf{5 . 7 2 0 0}$ & $\mathbf{7 5}$ & $\mathbf{1 . 7 0 5 0 0}$ \\
& Male & 8.4545 & 11 & 2.06706 \\
Non Blood Relatives Other & Female & 8.0000 & 10 & 1.76383 \\
& Total & $\mathbf{8 . 2 3 8 1}$ & $\mathbf{2 1}$ & $\mathbf{1 . 8 9 4 8 6}$ \\
& Male & 6.9143 & 35 & 2.18782 \\
\multirow{2}{*}{ Total } & Female & 6.9327 & 104 & 2.12367 \\
& Total & $\mathbf{6 . 9 2 8 1}$ & $\mathbf{1 3 9}$ & $\mathbf{2 . 1 3 2 0 2}$ \\
\hline Table 2. Anxiety for Males and Females Regarding Donor Group \\
\hline \multicolumn{4}{r}{} \\
& \multicolumn{4}{c}{}
\end{tabular}

\section{DISCUSSION}

As was observed, the average age of living kidney donor (LKD) was 45.58 years, and that majority of our study population is in the age group of 36 to 50 years. With similar study by Deborah Zimmerman et al., of the total of 146 living kidney donors and cadaveric donors, 42.1 years was the mean age for LKD. ${ }^{10}$ Organ transplantation and gender differences: a paradigmatic example of intertwining between biological and socio-cultural determinants Francesca. ${ }^{11}$ Most of our study population was rural $66.9 \%$. A study by Guleria, Singh, Kumar, Agrawal \& Agrawal in Kerala resulted in the urban area $84 \%$ and in rural area $95 \%$ of the participants were pro-organ donation of that $76 \%$ in urban area and $78 \%$ in rural area are willing to donate organs for transplantation if required. Trends of organ donation and awareness in Ernakulam, Keral. ${ }^{12}$

We found that majority donors were family members, most donors were married (74.3\%) the number of first degree relatives or 'close' relatives, but more members of the LDKT group had a family member volunteer to donate a kidney (2.8 vs. 1.0 , respectively, $\mathrm{p}<0.0001$ ). The influence of sociodemographic factors treatment perceptions and attitudes to living donation on willingness to consider living kidney donor among kidney transplant candidates. Lee found comparable results with respect to the carers' relationship with the donor, seven carers' who participated in the interview were spouses (30.4\%), six were parents (26.0\%), three were offspring (13.0 $\%)$, and seven were siblings (30.4\%). ${ }^{13}$

As observed in our study, females outnumbered males as donors for kidney transplant (74.8 \% vs. $25.2 \%$ ). The findings are consistent with the study by Puoti, et al. where, females were donors in two thirds (65\%) of cases and recipients only in one third (35\%). It is possible that, women have more selfsacrifice and sense of responsibility than men and therefore are more willing to donate their organs. Majority of the donors were family members, which could be because of the sense of altruism in family members. Another reason could be the "Transplantation of Human Organs Act" which prohibits commercial organ donation.

Our study had female spouses with mild anxiety with mean of 8.3 in a sample of 139 where male spouses fared higher with mean of 9.66. Similar results were seen in cohort of 825 LKDs $5.5 \%$ screened positive for anxiety, $4.2 \%$ screened positive for depression, and $2.1 \%$ reported regretting their donation in work of Courtenay Holscher. ${ }^{14}$ Our finding that $5.5 \%$ of LKDs screen positive for anxiety is similar to the $6 \%$ of a cohort of 48 Australian donors, lower than the $21 \%$ with anxiety in a cohort of 161 German LKDs, and substantially lower than the $67 \%$ with anxiety in a cohort of 45 Portuguese LKDs. The prevalence of anxiety in LKDs is also substantially lower than a US general population prevalence estimate of $18.1 \%$.

Living kidney donation is a very complex psychological experience for donor candidates as well as recipients. On one hand, donor candidates may feel under emotional pressure because without their donation recipients' mostly loved ones, quality of life and health may further deteriorate, ${ }^{15-16}$ and on the other, recipients may feel guilty for endangering donors' family members' health. ${ }^{17-18}$ This makes the pre-transplant 
stage for both parties a time of hope, vulnerability, worry, conflict, guilt and distress. ${ }^{19}$

Major concerns in a resource limited country like India are financial burden on families, apprehension of donor candidates regarding their own health during the donation process along with concerns about economic burden of procedure, the surgery, recovery and long-term outcomes of the procedure as well as the recipients' health with key issues such as organ rejection.

\section{Limitations}

Our study has limitations. As a single center study, the generalizability of our findings may be limited. Also, despite a sample size of 139 donors and excellent response rate, we may lack the power to detect additional associations between donor's personality characteristics, anxiety, and depression, due to the low prevalence of these outcomes. Additionally, our study used screening tools to describe symptoms of anxiety and depression rather than a diagnostic tool. Finally, the crosssectional nature of our survey prohibits examination of causal effects, but the prevalence estimates and risk factors provide insight and help identify those LKDs most in need of formal referral for mental health services.

\section{CONCLUSIONS}

None of the donors had any current or lifetime Axis I diagnosis. Relationship with the recipient was found to be the most significant motivating factor for organ donation and the probable protective factor against psychological distress. This study would be helpful in improving donor-recipient relationships through increased empathy, gratitude, and ability to participate in a life together post renal transplant.

Data sharing statement provided by the authors is available with the full text of this article at jemds.com.

Financial or other competing interests: None.

Disclosure forms provided by the authors are available with the full text of this article at jemds.com.

\section{REFERENCES}

[1] Singh NP, Kumar A. Kidney transplantation in India: challenges and future recommendation. MAMC J Med Sci 2016;2(1):12-7.

[2] National Organ and Tissue Transplant Organization. Available at: https://www.notto.gov.in/index.htm

[3] Horvat LD, Shariff SZ, Garg AX. Global trends in the rates of living kidney donation. Kidney Int 2009;75(10):108898.
[4] ANZDATA. 39th Annual Report. Registry Report. Adelaide, Australia: Australian and New Zealand Dialysis and Transplant Registry 2016.

[5] UNOS. United network for organ sharing. Data 2018. http:// www. unos. org.

[6] Canadian Institute for Health Information. e-Statistics on organ transplants. Waiting Lists And Donors 2017. https://www. cihi. ca/ sites/ default/ files/ document/ donor_section_v0.1_en_2017. xlsx2017.

[7] NHS Blood and Transplant. Activity report 2016-2017: NHS Blood and Transplant 2018.

[8] First MB, Spitzer RL, Gibbon M, et al. Structured clinical interview for DSM-IV Axis I Disorders. Research Version New York: Biometrics Research 2005.

[9] Zigmond AS, Snaith RP. The hospital anxiety and depression scale. Acta Psychiatr Scand 1983;67(6):36170.

[10] Zimmerman D, Albert S, Llewellyn-Thomas H, et al. The influence of socio-demographic factors, treatment perceptions and attitudes to living donation on willingness to consider living kidney donor among kidney transplant candidates. Nephrol Dial Transplant 2006;21(9):2569-76.

[11] Puoti F, Ricci A, Nanni-Costa A, et al. Organ transplantation and gender differences: a paradigmatic example of intertwining between biological and sociocultural determinants. Biol Sex Differ 2016;7:35.

[12] Guleria, K, Singh AK Kumar B, et al. Trends of organ donation and awareness in Ernakulam, Kerala. BMC Proc 2012;6(Suppl 4):48.

[13] Lee J, Lee WJ, Lee JM. Attitude favorability towards organ donation in family members of brain dead organ donors. J Korean Soc Transplant Korean 2014;28(4):219-25.

[14] Holscher CM, Leanza J, Thomas AG, et al. Anxiety, depression, and regret of donation in living kidney donors. BMC Nephrol 2018;19(1):218

[15] Burroughs TE, Waterman AD, Hong BA. One organ donation, three perspectives: experiences of donors, recipients, and third parties with living kidney donation. Prog Transplant 2003;13(2):142-50.

[16] Waterman AD, Covelli T, Caisley L, et al. Potential living kidney donors' health education use and comfort with donation. Prog Transplant 2004;14(3):233-40.

[17] Schweitzer J, Seidel-Wiesel M, Verres R, et al. Psychological consultation before living kidney donation: finding out and handling problem cases. Transplantation 2003;76(10):1464-70.

[18] Hanson CS, Chadban SJ, Chapman JR, et al. The expectations and attitudes of patients with chronic kidney disease toward living kidney donor transplantation: a thematic synthesis of qualitative studies. Transplantation 2015;99(3):540-54.

[19] Agerskov H, Ludvigsen MS, Bistrup C, et al. Living kidney donors' experiences while undergoing evaluation for donation: a qualitative study. J Clin Nurs 2015;24(1516):2258-67. 